\section{Reformas agrarias y sus rastros en ruralidades contemporáneas: los casos de Bolivia y Chile*}

Land reforms and its traces in contemporary ruralities: the cases of Bolivia and Chile

\section{Alejandra Ruiz-TarRÉs ${ }^{* \star}$}

\section{Resumen}

Durante el siglo pasado muchos países de América Latina pasaron por procesos de reformas agrarias cuyo espíritu fundamental era resolver el tema de la desigual distribución de la tierra desde la perspectiva de una necesaria inclusión social y política de grupos ampliamente marginados, pero también considerando al sector agrario como un sistema con grandes deficiencias respecto al aporte potencial que podía hacer al crecimiento económico. Varias décadas después, depositamos la mirada en estos sucesos históricos

\footnotetext{
Becaria CONICYT.

** Instituto de Estudios Avanzados (IDEA) de la Universidad de Santiago de Chile. Dirección: Román Díaz 89 CP: 7500618. Correo electrónico: alejandra.ruiz@usach.cl.
}

para reflexionar sobre nuestras ruralidades contemporáneas, específicamente para los casos de Bolivia y Chile. Nos interesa fundamentalmente observarcómo fueron llevadosa cabo los procesos de reforma agraria en estos países, para luego vislumbrar cuáles son las principales similitudes y diferencias que presentan y, finalmente, ponderar la incidencia de sus rastros bajo la hipótesis que plantea el estudio de estos acontecimientos como fenómenos significativos para la comprensión de conflictos rurales actuales.

Palabras clave: Reformas agrarias, ruralidad contemporánea, Bolivia, Chile

\begin{abstract}
During the last century many latin american countries went through processes of land reforms whose main spirit was to resolve unequal land distribution from the perspective of a necessary social and political inclusion of widely marginalized groups, but also considering the agricultural sector as a system whith great deficiencies concerning its potential contribution to economic growth. Several decades later, we fix our eyes on these historical events to reflect about our contemporary ruralities, specifically the cases of Bolivia and Chile. We are particularly interested in observing how were the land reform processes carried out in these countries, in order to consider the main similarities and differences that they present, and finally to weigh the incidence of its traces under the hypothesis that the study of these events as significant phenomena for the comprehension of current rural conflicts.
\end{abstract}

Key words: Land reforms, contemporary rurality, Bolivia, Chile 


\section{Introducción}

La Revolución Mexicana es ejemplo iniciático en las luchas por la redistribución de tierras en América Latina, luego vendrán otras experiencias cuyas formas y contenidos difieren bastante. Esta multiplicidad ha hecho que exista mucho debate respecto a cómo se conciben estos fenómenos y la importancia atribuida a su comprensión. Siguiendo nuestro propósito, reconocemos dos grandes modos de acercarse a su investigación: en primer lugar, autores que estudian estos procesos en su momento histórico particular; como, por ejemplo, Cristóbal Kay (1999), quien destaca como elemento primordial las transformaciones políticas producidas "desde arriba", donde las estructuras productivas agrarias estaban asociadas a altos niveles de ineficiencia, atraso, servidumbre, etc., por lo que aparece necesario impulsar procesos modernizadores enfocados a potenciar el crecimiento económico y generar divisas. También en esta esfera, hay quienes destacan los contextos sociopolíticos en que se insertaron estas transformaciones; así, Jaques Chonchol (2003) señala el ambiente de fuertes cambios políticos y presiones sociales que anteceden y acompañan a estos procesos. En segundo lugar, situamos a autores que consideran las reformas agrarias como momentos de transformación que permiten problematizar y comprender procesos contemporáneos; por ejemplo, Plinio Arruda que visualiza "a derrota da luta pela terra" (Arruda 2012: p.40) como lugar para reflexionar sobre lecciones que permitan avanzar en procesos de democratización en la sociedad brasileña. Por su parte, Sergio Gómez (1992) destaca el efecto traumático que tuvo la aplicación de la reforma agraria en Chile como elemento que coadyuva a comprender fenómenos posteriores en la configuración rural de este país. Mientras, Víctor Bretón, en el contexto de las transformaciones neoliberales, en Ecuador, señala "la importancia de releer la reforma agraria (...) en toda su complejidad histórica como una herramienta de comprensión de la realidad; y releerla también como parte de un camino de búsqueda de alternativas para los pequeños productores rurales glocalizados" (Bretón 2006: p.60)

En este campo de reflexión situamos nuestra investigación, bajo la hipótesis que propone el estudio de reformas agrarias como lugar reflexivo que abre posibilidades de comprensión de conflictos rurales contemporáneos. En las secciones 2 y 3 , hacemos una lectura de estos procesos en Bolivia y Chile ${ }^{1}$, a partir del análisis de las propuestas políticas y disposiciones legislativas que establecen las directrices prioritarias, considerando también a autores claves al respecto; finalmente, en la última sección, comparamos ambas experiencias, relevando las principales similitudes y contrastes entre ambos países, al tiempo que buscamos rastros que colaboren a la comprensión la incidencia de estos fenómenos en conflictos rurales contemporáneos.

\section{Reformas agrarias en Bolivia}

\subsection{El origen (1953-1964)}

La reforma agraria de Bolivia se desarrolla en el marco de la Revolución de 1952; siendo el segundo país de América Latina-después de

La elección de los países se da en el marco de una investigación mayor en curso, cuyo objetivo fundamental es comprender la configuración de acciones colectivas y pensamientos identitarios a partir de un conflicto específico: las semillas. 
México- donde una vasta revolución social origina el proceso de redistribución de tierras; luego vendrá Cuba y, después Nicaragua.

En el caso boliviano, las fuerzas que empujan las necesarias transformaciones son importantes rebeliones indígenas y campesinas; las que, posteriormente, junto a organizaciones de trabajadores urbanos, bajo la configuración de un movimiento social pluricultural, llegan al poder a través del Movimiento Nacional Revolucionario (MNR).

Los objetivos fundamentales del decreto de ley de Reforma Agraria (DL.3464) eran: abolir la servidumbre, eliminar el latifundio, distribuir las tierras a partir del lema "la tierra para el que la trabaja", restituir tierras usurpadas a comunidades indígenas, apoyar la tecnificación de las actividades productivas agrarias, crear vías de comunicación despejadas entre occidente y oriente, promover "colonizaciones" hacia el oriente $y$, finalmente, conservar los recursos naturales.

Para comprender estos procesos en Bolivia, es requisito inicial distinguir entre territorios del altiplano y valles occidentales de aquellos de los Ilanos orientales. La geografía, los entornos ecológicos, las culturas que conviven, los modos de organización política y administrativa, definen los trazos que permiten entender el devenir diferenciado de las tierras de Occidente y Oriente en este país.

Así, en Occidente, la eliminación del latifundio significó una importante parcelación de los territorios altiplánicos cuyo objetivo fundamental era abolir los sistemas hacendales de estructuración social y política, enfocada a una producción intensiva bajo la idea de colaborar con la subsistencia de familias campesinas, mas donde la consideración de las comunidades indígenas quedó muy pormenorizada. "La Ley de Reforma Agraria de 1953 fue ambigua con los ayllus y "comunidades" originarias. Esta falta de claridad no permitió brindar mejoras a los comunarios, aunque se toleró su reproducción como sistema socio-económico y político local" (Ticona 2003: 6). Mientras, en Oriente, la reforma planteó la eliminación del dominio latifundista tradicional a partir de un proyecto modernizador que, más que modificar los patrones de concentración y distribución de la tierra, promovió el desarrollo de empresas agrícolas y la configuración de neolatifundios, al tiempo que se implementan políticas de migración (principalmente interna) que promovían la colonización de vastos territorios poco explotados ubicados en las zonas tropicales o sub-tropicales, principalmente de los departamentos de Beni, Pando, Tarija y Santa Cruz².

Luis Antezana, por su parte, plantea que los cambios más importantes en cuanto a tenencia de tierra se produjeron en oriente ya que un porcentaje muy importante de las tierras de esta zona que eran de propiedad fiscal y correspondían a tierras baldías fueron redistribuidas de acuerdo a las necesidades de producción capitalista. Dirá el autor que este proceso en tierras orientales "(...) fue una distribución campesina, una revolución agraria democrática campesina" (Antezana 2011: p.29) Mientras en Occidente, plantea el

\footnotetext{
"La marcha hacia el Oriente" fue un proceso promovido en base a la desigual distribución de habitantes en los territorios bolivianos (alrededor del $80 \%$ de la población habitaba la zona altiplánica y de valles), así como también en la búsqueda por generar nuevos modos de asentamientos de familias campesinas que se encontraban en condiciones de empobrecimiento ampliado.
} 
autor; por un lado, las tierras de comunidades indígenas se mantuvieron casi en su totalidad bajo la misma condición; a su vez que, por otro lado, las haciendas de propiedad privada en la que sobrevivían los sistemas de servidumbre colonial, fueron intervenidas.

Desde la perspectiva del sistema productivo, Carlos Romero Bonifaz, señala que la reforma agraria de 1953 “(...) combinó la vía farmer en occidente, consistente en transformar la comunidad originaria tradicional en pequeña propiedad con mayor articulación al mercado capitalista, con la vía junker en el oriente, consistente en convertir la hacienda tradicional en empresa capitalista" (Romero 2008: 112)

A pesar de las importantes diferencias entre Occidente y Oriente, hay un elemento transversal: el componente indígena quedó oculto bajo el manto del campesino organizado, a pesar de la composición étnica del país. A partir de la Revolución de 1952, se produce un proceso de identificación de clases que desfigura los conflictos interétnicos que prevalecieron por largos períodos históricos. La lucha se reorganiza a partir de una ampliada sindicalización y organización de milicias rurales que terminarán por convertir a los indígenas parcialmente en campesinos; instalándose nuevas formas de vincularse con el Estado y los partidos.

\subsection{Dictaduras y retorno a la democracia (1964-1996)}

Varios textos recalcan la idea de que la reforma en el oriente no produjo una diferencia relevante en los modos de distribución y ocupación de los territorios; señalando, además, que la estrategia implementada en estos territorios adquirió especial carácter discrecional, sobre todo durante los regímenes militares que se sucedieron en el país desde 1964.

Carlos Romero Bonifaz muestra datos concretos sobre los períodos en que se realizan las mayores dotaciones de tierras en oriente, concluyendo: "Tres gobiernos (dos militares y uno $\mathrm{civil}^{3}$ ) repartieron el $60 \%$ de la superficie distribuida por el Estado". (Romero 2008: 117).

Luis Antezana, señala que se instaura un proceso contrarreformatorio a nivel nacional que estará marcado por irregularidades "(...) y hasta aberraciones en la distribución de tierras en oriente, en especial a partir de los años 1971 y 1980" (Antezana 2011: 113). Parte de las aberraciones tienen relación con las imbricaciones que se dieron entre los poderes político y económico con redes de narcotráfico, las que bajo regímenes autoritarios adquieren gran libertad de acción.

En el contexto de gran represión y niveles elevados de nepotismo, el 17 de septiembre de 1982 , se produce una huelga general organizada por la Central Obrera Boliviana (COB) que obliga a la dimisión del Gral. Guido Vildoso Calderón -uno de los ocho militares que ocuparon la figura presidencial entre 1978 y 1982- y que definirá la vuelta al frágil camino democrático con la llegada al poder de Hernán Siles Suazo. Bajo el gobierno de Siles Suazo, en 1984, la Confederación Sindical Única de Trabajadores Campesinos de Bolivia (CSUTCB) presentó un anteproyecto de ley de reforma agraria: la Ley Agraria Fundamental (LAF). La LAF plantea

Se refiere a los gobiernos del Gral. René Barrientos (1964-1968), del Cnel. Hugo Banzer (1974-1978) y de Jaime Paz Zamora (19891993). 
como uno de sus ejes centrales el cambio del lema "la tierra para el que la trabaja" por "la tierra para quien la trabaja personalmente" en la búsqueda por colaborar a una reformulación de la distribución de tierras -sobre todo respecto a la configuración neolatifundista de oriente- así como también bajo la concepción de reducir formas abusivas de trabajo; proponiendo, al mismo tiempo, modos de trabajo colectivo y asociativo como figura primordial para al acceso a los derechos sobre la tierra, buscando con ello el reconocimiento de unidades productivas de carácter familiar, comunitarias y asociativas.

\subsection{Ley INRA o Segunda Reforma Agraria (1996-2006)}

La década de los 90 se abre con fuertes movilizaciones indígenas de las tierras bajas que exigen el reconocimiento de sus territorios. Se llevan a cabo importantes marchas organizadas por la CIDOB (Confederación de Pueblos Indígenas del Oriente de Bolivia ${ }^{4}$ ). A consecuencia de estos procesos de emergencia social resulta la promulgación de la ley 1715, más conocida como ley INRA o segunda reforma agraria, bajo el gobierno de Gonzalo Sánchez de Lozada.

La ley INRA establece la necesidad de garantizar el acceso con equidad al recurso tierra, otorgar seguridad jurídica a los poseedores de la misma y promover el uso sostenible del recurso. Para la consecución de tales propósitos, fue preciso distinguir entre tipos de propiedad, reconociéndose los siguientes: el solar

\footnotetext{
La CIDOB nace en 1982 como una confederación de pueblos indígenas de las tierras orientales de Bolivia; no obstante, a medida que adquiere fuerza va incorporando la representación de pueblos originarios de otras zonas del país.
}

campesino, la pequeña propiedad, la mediana propiedad, la empresa agropecuaria, las tierras comunitarias de origen (TCO) y las propiedades comunarias. De estas categorías prediales, resulta interesante recalcar la concepción de TCOs como "espacios geográficos que constituyen el hábitat de los pueblos y comunidades indígenas originarias, a los cuales han tenido tradicionalmente acceso y donde mantienen y desarrollan sus propias formas de organización económica, social y cultural, de modo que aseguran su sobrevivencia y desarrollo". (Art. 41 1996: 13).

A ojos de múltiples analistas, la incorporación de estas formas colectivas de propiedad constituyó un importante avance para las comunidades indígenas; sobre todo, para aquellas de tierras bajas. En cambio, en el altiplano, el hecho de que la ley INRA dispusiera dos figuras de propiedad excluyentes: individual o colectiva, generó graves conflictos; pues, en base a la reforma agraria inicial (1953), se daban situaciones en que una persona contaba simultáneamente con distintos tipos de derechos sobre espacios de tierra. Mientras, en oriente, las comunidades originarias habitaban fundamentalmente territorios poco explorados y escasamente conectados. En general, a partir de la ley INRA, aquellas comunidades originarias que habitaban territorios orientales fuera del alcance de los negocios agroexportadores, han logrado lentamente obtener titulaciones de sus territorios.

Inicialmente, la ley INRA establecía un plazo de diez años para llevar a cabo el proceso de distribución de tierras a través del mecanismo de "saneamiento de tierras". El saneamiento de tierras implica la titulación de tierras y la solución de conflictos, a partir de la verificación del 
cumplimiento de la Función Social y la Función Económica Social ${ }^{5}$ de los predios. Más, como señalan Colque, Tinta y Sanjinés:

El proceso de "saneamiento" carecía de una clara y directa relación con la facultad del Estado, a través del INRA, de implementar una política de reforma agraria expresamente dirigida a revertir y expropiar tierras de la gran propiedad (Urioste 2009; Lavadenz 1995). Sin lugar a dudas, esta falta de conexión entre el procedimiento técnico-jurídico y el poder jurídico-político del Estado de recuperar el control sobre las tierras de gran extensión obstaculizó el proceso de distribución y redistribución de tierras. (Colque, G., Tinta, E., Sanjínes, E. 2016: 19)

La experiencia constata que el proceso de saneamientohasidomuchomáslentoyengorroso de lo que se planteó inicialmente. A lo señalado, se suma la falta de recursos con que se llevan a cabo estas reformas, siendo la principal fuente de financiamiento la cooperación internacional, teniendo como correlato esperable que los recursos son entregados para la consecución de ciertos propósitos prioritarios. Pero también existen dificultades para romper con estrategias clientelares, abusos de poder y corrupción.

\subsection{Reconducción Comunitaria de la Reforma Agraria (2006 en adelante)}

La ley 3545 de reconducción comunitaria surge de las dificultades encontradas en la ejecución del proceso de saneamiento de las tierras

\footnotetext{
La ley establece que "se entenderá que el Solar Campesino, la Pequeña Propiedad, las Propiedades Comunitarias y las Tierras Comunitarias de Origen, cumplen la función social, cuando sus propietarios o poseedores, demuestran residencia en el lugar, uso o aprovechamiento tradicional de la tierra y sus recursos naturales destinados a lograr el bienestar o desarrollo familiar o comunitario, según sea el caso, en términos económicos, sociales o culturales". Por su parte, la FES hace alusión al "empleo sostenible de la tierra en el desarrollo de actividades agropecuarias, forestales y otras de carácter productivo, así como las de conservación y protección de la biodiversidad, investigación y ecoturismo, conforme a su capacidad de uso mayor, en beneficio de la sociedad, el interés colectivo y el de su propietario". (Art 2).
}

emprendida a partir de la ley INRA. El 19 de octubre de 2006, se promulga la ley 3501 que amplía en 7 años el plazo para la ejecución de los procesos de titulación y saneamiento de tierras. Luego, el 28 de noviembre de 2006 se promulga la ley 3545 con carácter de transitoria, pues se encontraba en marcha el proceso de Asamblea Constituyente. Finalmente, en febrero de 2007, se presenta el Plan Estratégico Nacional de Saneamiento y Titulación de Tierras 2007-2013 (PENSAT) que, en base a la ley 3545, propone líneas estratégicas que buscan resolver el problema de la persistente desigualdad en la distribución de tierras. Este plan pretende agilizar y flexibilizar algunos procedimientos, pues los resultados del saneamiento a la fecha eran desafortunados:

(....) de las 106,75 millones de hectáreas bajo objeto de saneamiento, sólo se saneó un $28,33 \%$ (titulado $10,66 \%$ y por titular $17,67 \%)$; está en proceso de saneamiento un $14,91 \%$ y quedó sin sanear el $56,76 \%$. Además, en éste proceso el Instituto Nacional de Reforma Agraria (INRA) gastó 88,36 millones de dólares americanos (74,5\% recursos de la cooperación internacional y $25,5 \%$ recursos nacionales). (Nuñez 2007)

La reconducción comunitaria de la reforma agraria requiere de un Estado más activo e interventor. En esta dirección, la ley 3545 otorga atribuciones especiales al Poder Ejecutivo para controlar el cumplimiento de la Función Económico Social de los predios. En caso de incumplimiento con este principio básico, el Estado puede revertir los títulos y proceder a la posterior redistribución; priorizando el beneficio de las naciones, pueblos y comunidades indígenas originarias campesinas sin tierra o con poca tierra. Además, incorpora el mecanismo de "saneamiento interno" que constituye una propuesta enarbolada -durante la aplicación de la ley INRA- por las propias comunidades, tanto de aquellas que habitan zonas altiplánicas y de 
valles, como aquellas que se organizan bajo la Confederación Sindical de Colonizadores de Bolivia (CSCB). El saneamiento interno se planteó como una estrategia de resolución de conflictos sobre límites, derechos propietarios, sucesiones hereditarias y titulaciones que se realiza entre los mismos comuneros a través del diálogo y la búsqueda de acuerdos por medio de aprobación en asambleas ${ }^{6}$.

A su vez, en esta nueva ley, asoma la equidad de género como lineamiento imprescindible en el proceso de saneamiento y acceso a la tierra. A diciembre del 2012, se consolidaron los derechos sobre propiedad de la tierra para mujeres en un $46 \%$, mientras que para hombres un $53 \%$. No obstante, se ha visto que acceden a proporciones menores de tierra que sus pares masculinos; así también, persisten un sinnúmero de factores que dificultan el ejercicio concreto de estos derechos como pueden ser las normas consuetudinarias y los patrones culturales de ciertos pueblos y comunidades originarios indígenas campesinos.

Por otra parte, la Nueva CPE "introduce la complementariedad entre derechos colectivos e individuales, permitiendo -por primera vez- la titulación mixta de la propiedad, de acuerdo a las dinámicas que existen en las comunidades

\footnotetext{
La estrategia de "saneamiento interno" se dio inicialmente a partir del Decreto Supremo 26559, en el año 2002, donde se resuelve: "Reconocer el denominado "saneamiento interno", como instrumento de conciliación y resolución de conflictos aplicable al interior de colonias y comunidades campesinas, indígenas y originarias, a fin de reconocer los acuerdos internos a los que arriben sus miembros con la participación de sus autoridades naturales y originarias, aplicando normas propias, usos y costumbres, siempre que no vulneren la normativa vigente y no afecten derechos legítimos de terceros.(Art. $1^{\circ}$. DS 26559). Aun cuando, paradójicamente, dicho decreto establece en su artículo 6 lo siguiente: "Quedan excluidas del ámbito de aplicación del presente Decreto Supremo las comunidades indígenas afiliadas a la Confederación de Pueblos Indígenas de Bolivia - CIDOB"
}

campesinas e indígenas, especialmente las de valles y altiplano" (Chumacero 2010: 13-14).

Considerando que, a fines de octubre del año 2013, se dictó la ley 429 cuyo fin es establecer una nueva ampliación de los plazos -esta vez por cuatro años- para realizar el proceso de saneamiento de tierras, ciertamente aún quedan varios problemas por resolver, siendo quizás uno de los más importantes la necesaria redistribución de aquellas tierras de los llanos orientales que se encuentran todavía en manos de latifundistas que han ido entrabando los procesos para la comprobación de la FES en sus predios, movilizando recursos económicos y políticos de manera de obstaculizar la reconversión de tierras para su posterior redistribución.

\section{Reforma agraria en Chile}

\subsection{El origen (1959-1964)}

Los inicios de la reforma agraria chilena se entreveran en la discusión internacional, comandada por EE.UU y su propuesta de Alianza para el Progreso, que formulaba la idea de avanzar en procesos paulatinos -moderadosde redistribución de tierras; previniendo el efecto que la Revolución Cubana tenía en la política latinoamericana.

En Chile será la impronta modernizante, con fuerte énfasis técnico-tecnológico, la que configura de manera importante el diseño inicial de reforma agraria. Se hace hincapié en la necesidad de incrementar la producción agraria (y su productividad) asociándola a una demanda interna de alimentos mucho mayor que la capacidad tecnológica instalada. 
En agosto de 1962 se elabora la primera ley de reforma agraria (Ley 15.020) y, con ella, la creación de tres organismos orientados al desarrollo rural: Corporación de la Reforma Agraria (CORA), Instituto Nacional de Desarrollo Agropecuario (INDAP) y Consejo Superior de Fomento Agropecuario (CONSFA).

Durante el gobierno de Jorge Alessandri Rodríguez, al no haber intención de trastocar el orden latifundario existente, la estrategia se concentra en intentar aumentar la producción agraria a partir de la subdivisión de tierras fiscales. En el acostumbrado mensaje presidencial de los 21 de mayo, aquél correspondiente al año 1960, el Presidente Jorge Alessandri expresa:

Toda verdadera reforma agraria debe empezar, a juicio del Gobierno, por incorporar al dominio privado esta valiosa extensión de nuestro suelo (tierras pertenecientes al Estado y a las diversas instituciones del sector público), que no siempre están trabajadas de manera conveniente y cuya incorporación al dominio privado habrá de traer positivos beneficios, pues, es evidente que el propietario particular, contando con la debida asistencia técnica, sabrá explotarla de manera más útil para nuestro desenvolvimiento económico. (Cit. en Garrido, Guerrero y Valdés 1988: 85)

A pesar de que este período pasó a la historia como "la reforma de los maceteros" por el escaso alcance que tuvo; es destacable la instalación política e institucional de este fenómeno; pues, posteriormente, se dio pie a un proceso de transformación profundo y concreto.

\subsection{La Reforma Agraria Social Cristiana (1964-1970)}

Ya en tiempos de Alessandri Rodríguez algunos sectores de la Iglesia Católica habían levantado el tema de distribución de tierras como una cuestión urgente de resolver. En 1961, un grupo de párrocos de la provincia de Aconcagua señala al presidente la urgencia de una reforma orientada a que quienes trabajan la tierra puedan poseerla, "aunque no resulte todo lo técnicamente perfecta que fuere de desear (...)" (Garrido, Guerrero y Valdés 1988: 90). Algunos obispos y arzobispos emprendieron procesos reformistas en terrenos que pertenecían a la iglesia; siendo ejemplo original el Obispo de Talca, Manuel Larraín Errázuriz, formando una cooperativa campesina el 26 de junio de 1962. A partir de estas experiencias, con el financiamiento de MISEREOR (Organización de obispos alemanes de cooperación para el desarrollo), en 1963, surge el Instituto de Promoción Agraria (INPROA) conformado por un equipo técnico laico compuesto primordialmente por militantes demócratacristianos.

En noviembre de 1964, el candidato demócrata cristiano Eduardo Frei Montalva gana las elecciones. Durante su gobierno se dictan dos leyes de particular trascendencia para el devenir rural chileno: la segunda ley de reforma agraria (Ley 16.640) y la ley de sindicalización campesina (Ley 16.625); ambas dictadas el año 1967.

Después de numerosos intentos, los trabajadores rurales logran organizarse en sindicatos, federaciones provinciales y confederaciones nacionales. En 1967, se forman 216 sindicatos que contaban con 53.199 socios; en 1970 ya existían 466 sindicatos con 137.001 socios (Santana 2006: 38); tendencia que seguirá con aún mayor fuerza durante la Unidad Popular. Además, señala José Bengoa:

(...) junto a la organización sindical se desarrolló enormemente la organización cooperativa, llegándose a formar alrededor de 200 cooperativas de campesinos y más de 2.100 comités de pequeños productores. El 
Estado fomenta por medio del Instituto de Desarrollo Agropecuario (INDAP) y del Instituto de Capacitación e Investigación en Reforma Agraria (ICIRA) la organización de estos sectores, los apoya y les entrega capacitación. (Bengoa 1983: 33)

La idea del cooperativismo era fundamentalmente lograr que los campesinos, a través de su organización, consiguieran potenciar y hacer más eficiente la gestión de los recursos disponibles, incluida su fuerza de trabajo, de manera de aumentar la producción agraria, incidiendo con ello en el bienestar social de sus familias, pero también en el desarrollo económico del país. Todo lo anterior a partir de una experiencia donde las obligaciones y beneficios son colectivos.

La ley 16.640 o segunda ley de reforma agraria, tenía como objetivos básicos: aumentar la producción agraria nacional; distribuir y otorgar titulación de tierras a miles de campesinos que trabajan la tierra; para, finalmente, mejorar de las condiciones de vida y laborales de los habitantes rurales. Se estableció un procedimiento donde CORA resolvía las causales de expropiación de predios (superficie mayor a $80 \mathrm{HRB}$, predio abandonado $\mathrm{y} / \mathrm{o}$ mal explotado); aunque también existía una suerte de expropiación voluntaria. Es necesario recalcar que el artículo $16^{\circ}$ de la ley 16.640 establecía la posibilidad de conservar un máximo de 80 hectáreas para aquellos productores agrícolas que son eficientes en su producción. Este artículo será decisivo para la conservación de tierras más productivas por parte de terratenientes y sectores de la emergente «burguesía agrícola». Además da cuenta de la "dualidad de la propuesta demócrata cristiana", planteada por Heidi Tinsman (2009), quien señala que esta propuesta era muestra de las divisiones internas del partido, al tiempo que:
(...) era reflejo de la convicción, compartida por las tendencias del partido, de que el capitalismo podía ser simultáneamente más eficiente y más democrático, sin desatar un conflicto de clases. Desde su perspectiva los campesinos podían organizarse, recibir tierras y gozar de un mejor nivel de vida, sin poner en peligro la producción agrícola o castigar a aquellos latifundistas que producían en forma eficiente (Tinsman 2009: 100)

Se establecen los asentamientos campesinos como mecanismo básico de asignación de tierras, que buscaba dos propósitos: “(...) preparar a los campesinos para la gestión externa y explotación interna de las futuras explotaciones definitivas. Darse un plazo de cinco años para las inversiones complementarias necesarias (viviendas, caminos, bodegas, etc)" (Chonchol 2006: 3)

Por otra parte, entre 1960 y 1965 se produce un gran movimiento de división de tierras; las grandes haciendas se "hijuelan" en predios menores repartidos entre familiares cercanos. Tan fuerte resultó ser el fenómeno de subdivisión de tierras que, en 1965, se dicta una ley (Ley $\left.N^{\circ} 16465\right)$ donde se establece la prohibición de hacer subdivisiones de tierras sin previa autorización de CORA.

\section{A esto se suman los fuertes contrastes regionales} en el proceso distributivo. José Bengoa destaca que en la zona norte se benefició a un número mucho mayor de campesinos que en la zona sur, pues en las provincias de Valdivia, Osorno y Llanquihue, el peso de los grandes propietarios era más significativo. Por otra parte, en la Araucanía, se va consolidando un fuerte movimiento mapuche cuyo propósito es recuperar tierras usurpadas y ampliar sus territorios de acuerdo a los Títulos de Merced que habían sido persistentemente transgredidos por grandes latifundistas bajo la anuencia del Estado chileno. Las "tomas de fundos" y las 
"corridas de cerco" por comunidades mapuche y sus aliados políticos, fueron las principales estrategias utilizadas por estos actores para reivindicar la restitución de sus territorios, pues "los mapuche no fueron considerados en su especificidad en la ley 16.640" (Correa et. al, 2005, p.105). Tal como lo plantean los autores, la ley de reforma agraria tenía carácter general y nacional, mientras la demanda mapuche estaba situada localmente, con contenidos culturales y comunitarios que la ley no contemplaba.

\subsection{La Unidad Popular y la Reforma Agraria (1970-1973)}

Con la Unidad Popular en el gobierno hubo un mayor empuje a las expropiaciones iniciadas durante el período anterior. Entre 1970 y 1973 se ejecutaron más del $60 \%$ del total de expropiaciones realizadas durante la reforma agraria chilena. "Además, este rápido y masivo cambio de tenencia de la tierra fue hecho casi sin violencia y sin disminuir el área sembrada ni la producción agropecuaria global, caso único en reformas agrarias de esta envergadura", dirán Barraclough y Affonso (1973).

La vasta reducción de tierras latifundistas se explica fundamentalmente por la redistribución de tierras (35\% de superficie productiva), pero también por el amplio proceso de subdivisión e hijuelación de latifundios. Cerca del $30 \%$ de terrenos agrícolas correspondían a medianas y grandes propiedades que se habían formado de esta manera.

Con el gobierno de la Unidad Popular, las estrategias consideraban necesaria una participación más activa de los habitantes rurales a través de sus organizaciones. Así, el 21 de diciembre de 1970, se establece un decreto $\left(\mathrm{N}^{\circ} 481\right)$ a partir del cual se crea el Consejo Nacional Campesino con la intención de otorgar una intervención más directa a los trabajadores en la organización productiva rural.

Por su parte, los asentamientos se organizaban a partir de una combinación de tierras colectivas y tierras individuales, donde cada asentado contaba con una porción de tierras destinada a la subsistencia familiar, al tiempo que debía trabajar de manera colectiva en las tierras comunitarias cuyo propósito era aportar a la producción nacional. Los asentamientos redundaron en un gran avance en la calidad de vida de quienes pudieron acceder a esta forma de dotación de tierras; pero "incluían solo entre el 10 y a un 15 por ciento de los trabajadores agrícolas varones del Valle del Aconcagua y de todo Chile" (Tinsman 2009: 193). Los asentamientos se organizaban a través de asambleas y consejos campesinos, lo que otorgaba la sensación de ser capaces de orientar sus vidas y ser un aporte al país. No obstante también conllevó conflictos, sobre todo en relación a un amplio número trabajadores agrícolas que aspiraban formar parte de algún asentamiento y tener acceso a los derechos y privilegios que en estos territorios se extendían. También estaban los minifundistas y empleados de exhaciendas, que no fueron considerados dentro de las prioridades de la reforma agraria; los primeros, mantenían precarios niveles de subsistencia y, los otros, mantenían fuertes lazos de dependencia material y simbólica con sus empleadores antiguos. Frente a estos problemas se crearon los Centros de Reforma Agraria (CERA) que buscaban corregir algunas de las dificultades que los asentamientos marcaban, teniendo como propósito integrar a quienes se encontraban pormenorizados en la organización de la producción agraria nacional. A partir de 1971, se pone en marcha un acuerdo 
de restitución de tierras a comunidades mapuche conocido como "El Cautinazo". Este fenómeno estuvo frecuentemente acompañado de tomas de fundos y corridas de cerco; pero ahora estas formas reivindicativas de tierras por parte de comunidades mapuche, empezaron a ser resistidas por grupos paramilitares que se organizaron al alero de organizaciones de extrema derecha

Así, mientras los niveles de organización campesina se incrementaban, los conflictos se agudizaban. La Democracia Cristiana se había aliado con el Partido Nacional formando parte de la oposición a la Unidad Popular, varias organizaciones campesinas querían sentar las bases de su autonomía de los aparatos institucionales y partidarios, los partidos luchaban entre sí por la preeminencia en el campo, la propiedad comunitaria basada en los asentamientos era ampliamente cuestionada por algunos sectores, así como también lo fueron los territorios de reserva de los grandes propietarios. Existían fuertes disputas entre campesinos y asalariados agrícolas temporales $y$, por otro lado, se agrupaban intereses de trabajadores rurales con trabajadores urbanos en el contexto de agudización de la lucha de clases propia del período.

\subsection{Dictadura (1973-1989)}

Con el golpe militar lo único que sobrevivió fue la eliminación del latifundio como figura dominante en el paisaje rural. Durante los primeros años, las autoridades dictatoriales se dedicaron a "regularizar" y "parcelar" los terrenos expropiados. De acuerdo a lo planteado por Bengoa (1983), las principales estrategias de regularización de tierras fueron, por una parte, la devolución completa de predios a sus antiguos dueños a partir de la revocación de decretos de expropiación y, por otra parte, la restitución de la reserva de tierras de las $80 \mathrm{HRB}$ consideradas en la legislación agraria. A esto hay que agregar los predios "traspasados por CORA a otras instituciones con diversos objetivos" (Garrido, Guerrero y Valdés 1988: 182)

En 1975, a partir del decreto de ley $\mathrm{N}^{\circ} 1107$, se crean las Sociedades de Cooperación Agraria (SOCA), figura que transforma los asentamientos campesinos en varias unidades agrícolas familiares (UAF), de propiedad individual y en donde las instalaciones, maquinarias, etc. son de uso común.

Bajo el contexto de regularización de predios expropiados, a partir del decreto de ley 2247 (junio de 1978), se establece que los campesinos asentados tendrán derecho a comprar el predio en que viven y desarrollan sus actividades productivas "cuando hayan adquirido la capacidad económica y empresarial suficiente para explotarlos en condiciones normales de eficiencia y sin dependencia del Estado, o en caso contrario, atender sus necesidades de trabajo, subsistencia y capacitación" (Considerando $\mathrm{N}^{\circ}$ 3 DL 2247). La tierra pasó a ser un bien más de transacción en el mercado. Así también, el agua se escinde de su significado ancestral de bien común, transformándose en propiedad de quienes están en condiciones de adquirir los llamados "derechos de agua".

A partir de 1977, una vez que el modelo neoliberal había adquirido cierta solidez en otros sectores de la economía, las decisiones frente al sector agropecuario nacional se orientaron, en primer lugar, a transferir el manejo de precios de productos básicos a la fluctuación de los mercados. Luego, se desliga el antiguo 
poder de compra del Estado y se privatizan los mecanismos de comercialización y distribución de los productos. Finalmente, se disminuye la asistencia técnica y la dotación de créditos a pequeños productores.

Sereorganizan los usos de los suelos emergiendo el sector forestal como un gran nicho de mercado. "Uno de los efectos perversos que se generaron durante el gobierno militar es que sólo cuatro o cinco empresas fueron las que aprovecharon más del $70 \%$ del subsidio forestal, lo cual hizo que esas empresas presionaran a la venta de tierras de pequeños productores que fueron desplazados." (Gómez 2006)

Junto con la reorganización de la producción agropecuaria y forestal, se desplegó un nuevo proceso de pauperización del campesinado, muchas veces acompañado de corrientes migratorias hacia las urbes, por entonces también con altas tasas de cesantía. Frente a tal problema, se emprendió la construcción de villas rurales para aglomerar a la población campesina desplazada de la tierra y, también, como alternativa de asentamiento a amplias capas marginales de las urbes más importantes.

\subsection{Democracia concertada (1989 en adelante)}

En la serie de gobiernos que se han sucedido desde el pacto de transición democrática hasta el actual gobierno de Michelle Bachelet, no se ha planteado en el país la necesidad de una distribución de tierras que considere la inclusión social y política de amplias capas marginadas, habitantes de territorios rurales en Chile.

Durante este extenso período, la configuración de la producción agropecuaria y forestal siguió el curso delineado bajo la dictadura, agregando el sector pesquero y las semillas como nuevas fuentes de negocios. Hay una continuación en el fortalecimiento del sector exportador, haciendo hincapié en la inversión en $\mathrm{I}+\mathrm{D}+\mathrm{i}$, al tiempo que se exige flexibilización laboral y amplias garantías jurídicas respecto a la propiedad privada. Se firman numerosos tratados de libre comercio, quedando la economía chilena como una de las más abiertas (expuestas) del mundo.

A partir de la capacidad de generar sinergias que potencien el crecimiento de las exportaciones del sector piscisilvoagropecuario ${ }^{7}$, se fundamentan las decisiones de organización agraria en el país, donde además se presentan elevados niveles de concentración de la tierra. Esta estructura de tenencia de la tierra será una de las mayores dificultades que ha encontrado el modelo para alcanzar el carácter de potencia mundial, por ello se han enarbolado un sinnúmero de políticas públicas que bajo la denominación de inclusión social plantean la integración de los pequeños productores a los encadenamientos productivos cuyos negocios están orientados a las exportación de recursos naturales y productos alimentarios.

\section{Comparando procesos y encontrando rastros}

Las reformas agrarias de Bolivia y Chile son bastante disímiles; tanto por los momentos sociohistóricos que explican su instalación, como por las concepciones y estrategias que fueron definiendo los contornos de su realización.

Concepto acuñado en el informe del PNUD sobre Desarrollo Humano en Chile Rural (2008). 
Aunque ambos países encuentran en su origen una propuesta modernizante que busca generar sinergias para una mayor y mejor producción alimentaria; los proyectos políticos que empujan inicialmente ambos procesos son muy diferentes. En Bolivia, "(...) la "reforma agraria" nació asociada a las históricas luchas campesinas para la abolición de haciendas y restitución de las tierras usurpadas" (Colque, G., Tinta, E., Sanjínes, E. 2016: 29); mientras en Chile obedece al cumplimiento de directrices políticas internacionales, cuyos contenidos iniciales estuvieron marcados por un signo técnico y donde las estrategias se enfocan al ámbito productivo, más que a una necesidad de reforma social. No obstante, luego del gobierno de Jorge Alessandri, los propósitos de la Reforma Agraria incorporan las demandas que los movimientos, campesinos e indígenas, habían estado enunciando desde larga data, dando curso a un importante -aunque breveproceso de transformación social.

Por tanto, al poco andar, ambos países-cada uno en su propio tiempo histórico- se encontraban implementando estrategias de redistribución de tierras que consideraban el lema "la tierra para el que la trabaja" como consigna directriz. A partir de la implementación del "modelo de sustitución de importaciones", apelando a una necesaria modernización e industrialización que permitiera reducir los vínculos de dependencia históricos que se establecen desde la época colonial, se comienzan a desenvolver movimientos sociales desde abajo y políticas de Estado desde arriba, que encaminarán la promoción de estrategias de desarrollo rural que rompen con la estructura hacendal y abren paso a la implementación de nuevas alternativas. Mas el desarrollo social enarbolado bajo la consigna "la tierra para el que la trabaja", ocultaba bajo su manto un sinnúmero de conflictos que se desenvolvían entre grupos culturalmente diversos: indígenas-no indígenas; hombres-mujeres; adultos-jóvenes. De esta manera, en Chile, las luchas emprendidas por el movimiento mapuche en la búsqueda por alcanzar la recuperación de tierras usurpadas y la ampliación de sus territorios, tuvo que buscar estrategias novedosas -"tomas de fundos" y "corridas de cercos"- para poder instalar sus demandas, ya que éstas se encontraban fuera de los propósitos que la reforma agraria había consignado. En Bolivia, en cambio, a pesar de que se reconoce desde el principio la propiedad comunitaria como figura predial en Occidente, se buscaba sobre todo dar pie a un proyecto emancipatorio de gran contenido social que, sin embargo, adeudaba la incorporación del componente indígena tan significativo en los territorios rurales de este país. Así, por la ausencia transversal del reconocimiento indígena, los objetivos no resueltos por la reforma agraria de 1953 tienen que ver con la conservación de los recursos naturales y la restitución de tierras usurpadas a comunidades indígenas. No obstante, una vez que los movimientos sociales llegan nuevamente a controlar el poder del Estado, esta vez bajo la representación de Evo Morales, los saberes y prácticas indígenas llenan de contenido el nuevo proyecto social emprendido en Bolivia. Muestra de ello es la instalación de la idea de territorio como lugar desde donde la enunciación de propuestas distributivas de tierras, concibe a las comunidades indígenas como principal actor de esta nueva etapa reivindicativa. En Chile, en cambio, el momento de mayor alcance para la demanda territorial mapuche fue durante el gobierno de Salvador Allende, cuando se establece la necesidad de avanzar en base al compromiso de hacer justicia frente abusos de larga data por parte de latifundistas privados y 
el Estado chileno, mas también por la fuerza con que el movimiento mapuche se había dispuesto a resolver los conflictos territoriales en la Araucanía. Será este breve lapso, el momento en que se incorporan componentes indígenas a la distribución de tierras en este país, bajo la comprensión de la organización territorial nacional también desde argumentos culturales y no puramente técnicos-productivos.

Con las dictaduras militares: en Bolivia múltiples y reiteradas, en Chile una sola, tajante y profunda; se potenció el modelo de los agronegocios en ambos países. En Bolivia, específicamente en tierras orientales, a partir de la imbricación de intereses de grandes terratenientes con la penetración de capitales transnacionales. En Chile, los militares y sus aliados neoliberales fomentaron la industria forestal, al tiempo que privatizaron recursos naturales e industrias estatales, mientras se devuelven ampliamente las tierras reformadas a sus antiguos dueños. Todos los alcances sociales de redistribución de las tierras en Chile, así como el desarrollo de capacidades organizativas y de emergencia social, fueron extintos por el autoritarismo de Estado que permaneció durante tantos años. No obstante, las estrategias agrarias dictatoriales no implicaron un reverso a las condiciones hacendales de otrora, la impronta apunta a establecer agroindustrias orientadas a la exportación. La democracia concertada llega en un escenario preconfigurado jurídica, material y simbólicamente, donde el entramado societal se encuentra muy fragilizado; marco óptimo para la prosecución del estrecho vínculo entre Estado y mundo empresarial. Bajo la mirada de las tierras como suelos productivos, se apoyan procesos de privatización transnacional sobre los recursos chilenos. En Bolivia esto también sucede, pues la presión de empresas transnacionales por acceder a nuevas y mejores garantías para hacer negocios (disfrazados de inversión) en países periféricos con una rica diversidad de recursos naturales, ha colaborado a la conformación de una estructura productiva donde los monocultivos y la transnacionalización de algunos sectores también marcan su huella. No obstante, en este país, serán movimientos indígenas y campesinos los que, dentro de sus reivindicaciones, elaboran estrategias que buscan profundizar y corregir los modos de tenencia y titulación de tierras, así como esclarecer los principios regidores para la ejecución de dichos procesos. Aparece entonces el tema indígena como elemento significativo a la hora de instituir nuevas configuraciones. Este escenario adquirirá aún más fuerza con la llegada a la presidencia de Evo Morales. Desde entonces, la incorporación de las demandas de comunidades indígenas campesinas originarias constituye eje primordial, llegando incluso a instalar categorías y modos de resolución propios, así como fijar prioridades cuyos fundamentos últimos se encuentran establecidos en la Nueva Constitución del Estado Plurinacional de Bolivia.

En cambio, en Chile, el fin de la dictadura se establece a partir de un pacto consignado entre cúpulas partidarias que acuerdan una vuelta a la democracia que respeta y adhiere a los marcos constitucionales que el régimen militar hereda hasta nuestros días; con ello, las posibles propuestas de reforma agraria se ven sepultadas, pues además no hay organizaciones sociales que sean capaces de contrastar un modo alternativo de configuración rural. En este escenario, las estrategias de organización de los suelos estarán presididas por el establecimiento de clústeres y encadenamientos productivos enfocados al fortalecimiento de agronegocios de 
exportación que promuevan el encumbramiento de Chile hacia una Potencia Alimentaria y Forestal Mundial ${ }^{8}$. De acuerdo a los datos presentados en el último Censo Nacional Agropecuario y Forestal (2007), en Chile existen 221.171 explotaciones correspondientes a micro o pequeñas explotaciones (73,4\%), 57.283 explotaciones medianas (19\%) y 22.922 grandes explotaciones $(7,6 \%)$. Estas últimas (grandes explotaciones) concentran alrededor del $90 \%$ de la tierra en Chile. Si incorporamos el factor étnico, tenemos que alrededor del $18 \%$ de los agricultores pertenece a algún pueblo originario y cuentan con alrededor del $2 \%$ de la superficie. Es decir, la estructura de tenencia de la tierra alcanza elevadísimos niveles de concentración.

Mientras, en Bolivia, distintos análisis coinciden en la observación de una transformación en la estructura en la tenencia de la tierra en este país. De acuerdo a los datos del INRA, elaborados por CIPCA (2013), en el período que va de 1953 a 1992 la proporción de hectáreas tituladas en manos de empresas y medianos propietarios era del 68\%; mientras, durante el período que va de 1996 hasta el año 2012, la hectáreas tituladas para empresas y medianas propiedades es de tan sólo un $7 \%$.

(...) en 16 años de aplicación de dichas Leyes, entre 1996 y 2012, el sector indígena originario campesino ha logrado consolidar 36,55 millones de hectáreas; es decir, duplicar la superficie lograda a 1992. Entonces, (...), preliminarmente se puede sostener que hay cambios sustanciales en la estructura de la tenencia de la tierra en el país, con mayor acceso de indígena originario campesinos a este recurso

\footnotetext{
Convertirse en potencia alimentaria significa estar dentro de los diez primeros lugares del ranking mundial de principales países exportadores de alimentos. Esta meta-país fue asumida por primera vez durante el gobierno de Ricardo Lagos, aunque su operacionalización se realizó durante el primer gobierno de Michelle Bachelet.
}

en comparación a lo que sucedía hace dos décadas. (Soliz y Núñez 2013: 5)

No obstante estos cambios contundentes en la distribución de tierras en Bolivia, principalmente dirigidas hacia comunidades indígenas campesinas en territorios orientales; en entrevistas a investigadores bolivianos/ $a^{9}$, se recalca la necesidad de matizar estas aseveraciones; pues, por un lado, las tierras que se han distribuido en Oriente a comunidades indígenas son fundamentalmente tierras estatales, dejándose ampliamente de lado la fiscalización del cumplimiento de la FES de los predios en manos de agroindustrias o grandes productores; por otra parte, en la Cumbre Agropecuaria, realizada en abril de 2015, en Santa Cruz, se decidió ampliar la frontera agrícola hacia sectores subtropicales y tropicales, lo que pone en entredicho los acuerdos establecidos con organizaciones indígenas y campesinas respecto a la protección de dichas reservas naturales y su biodiversidad, tanto como el compromiso que habría adquirido el proyecto de "Revolución rural, agraria y forestal", en el que se establecía la creación y fortalecimiento de condiciones que pudieran colaborar en la consecución de la seguridad y soberanía alimentaria para el país, siendo éste uno de los pilares del patrón de desarrollo ${ }^{10}$ delineado a partir de la amplia participación social que tuvo el

\footnotetext{
Las entrevistas fueron realizadas en el marco de la investigación más amplia mencionada en la introducción. En Bolivia, se entrevistó a investigadores de organizaciones no gubernamentales que trabajan directamente con comunidades indígenas y campesinas: Fundación Tierra, Programa NINA-Unitas, AGRUCO, CENDA, FOBOMADE. Además, se realizaron entrevistas a dirigentes de los principales movimientos indígenas y campesinos.

10 En base al estudio de los distintos planes de desarrollo enunciados en Bolivia desde 2006 en adelante, es factible señalar que el patrón de desarrollo boliviano se sustenta sobre los siguientes pilares: Vivir Bien, Socialismo Comunitario, Economía Plural, Seguridad con Soberanía alimentaria, Respeto y Protección a la Madre Tierra, Complementariedad de Saberes.
} 
proceso constituyente. No obstante el esquema teórico emanado, las prácticas institucionales han seguido un curso divergente a los acuerdos adquiridos con las comunidades. Como señala Miguel Urioste: "lamentablemente, el país y nuestras autoridades han tomado una opción por el agronegocio y en la expansión acelerada de la frontera agrícola. En este contexto, seguir pensando en una economía familiar de base campesina fuerte y dinámica es cada vez más difícil, si no imposible. Afirmar que Bolivia tiene un modelo diverso en el que conviven y se complementan la agricultura familiar y el agronegocio, no es cierto" (Urioste 2014: 105)

Observamos que las lecturas sobre las transformaciones sociales conseguidas a partir de la implementación de una reforma agraria, dependen considerablemente de cómo se conceptualiza la "distribución de la tierra"; pues si la reforma alude a una idea de reorganización de los territorios en términos prioritariamente productivos, enfocados al crecimiento económico, entran en juego argumentos distintos respecto a una reforma que se enfrenta a resolver cómo combinar los aspectos productivos con elementos culturales que permitan desplegar plurales formas de ser y hacer en territorios rurales. Pues finalmente, ¿qué se distribuye en una reforma agraria? ¿se distribuye sólo la tierra como recurso? o, en otras palabras, ¿es el paradigma productivo lo que define prioritariamente a una reforma agraria?

Como ha sido señalado, los modos de concebir las reformas agrarias tienen relación con proyectos políticos que empujan hacia una rearticulación de los grupos sociales con el territorio que los cobija, integrando en ello la necesidad de hacer transformaciones productivas y tecnológicas que se enfoquen hacia el mejoramiento de las condiciones de producción y la apertura de oportunidades comerciales; mas también tiene relación con cómo se entiende la convivencia entre diferentes proyectos socioculturales que en estos territorios se desenvuelven, en el contexto de una organización jurídica-administrativa nacional. Aunque existen varias formas de clasificar y tipificar las reformas agrarias, la discusión siempre llega al punto de reflexionar en torno a sus motivaciones y alcances como proyecto político; pues la distribución de tierras, al generar una estructura de organización básica de procesos productivos, sociales y culturales en territorios rurales, se encadena inexorablemente con modelos de desarrollo que sustentan comprensiones sobre cómo se deben organizar las sociedades y sus producciones, para quién y cómo, bajo qué propósitos y con cuáles énfasis.

Hemos visto que Chile actualmente se acerca mucho más a una comprensión técnica y productiva de la organización de sus territorios, bajo un modelo neoliberal dominante, que durante el último tiempo ha ido incorporando cuestiones medioambientales; pero cuyas cifras y normativas dan cuenta de un modelo con privilegios que potencia una relación clientelar entre el Estado y las comunidades campesinas e indígenas, donde no hay reconocimiento a las diferencias culturales en tanto prácticas y/o saberes capaces de aportar al desarrollo; sino más bien un reconocimiento de la diversidad como distinción que ayuda a caracterizar los productos de exportación. Mientras en Bolivia actual, vemos que el modelo de desarrollo rural predominante se afirma en una diversidad de actores colectivos que logran disputar las formas de definir prioridades para 
el establecimiento de matrices productivas en territorios rurales, aun cuando la fuerza de las agroindustrias transnacionales sea de dimensiones considerables y logre muchas veces imponer sus privilegios, en alianza con las autoridades políticas, por sobre los derechos establecidos en la Constitución política del Estado Plurinacional de Bolivia.

Frente a estos disímiles panoramas, nos preguntamos ¿Cuáles son los rastrojos que estos procesos reformatorios delegan a las ruralidades contemporáneas? ¿En qué medida la organización de la tenencia de la tierra -junto a las posibilidades que ello abriga- define los contornos de los conflictos presentes?

En principio, advertimos que la eliminación de la estructura hacendal definió una disposición de tierras que facilitó el ingreso próspero de los negocios agroexportadores en ambos países. En Bolivia, a partir de la reforma agraria de 1953, se genera una estructuración de la distribución de la tierra donde "en el espacio territorial conformado por valles y altiplano, correspondiente a sólo un tercio del territorio nacional las unidades familiares fueron fraccionadas llegando al límite, al extremo que tenemos unidades que son insuficientes para la sobrevivencia de una familia" (Vargas 2004: 16), mientras "dispone enormes extensiones de tierras de la llanura amazónica-chaqueña para la oligarquía circunstancialmente desplazada del gobierno, promoviendo así la formación de un nuevo tipo de latifundio y bloque de poder en el oriente boliviano". (Lizárraga y Vacaflores 2012: 17-18). Será esta figura la que posteriormente facilitará la instalación agroindutrias asociadas a la exportación de commodities, en Santa Cruz y sus alrededores. En cambio, en Chile, la reforma agraria que va de 1965 a 1973, junto al propósito de quebrar un sistema de dominación territorial -material y cultural- a partir de la creación de un área de propiedad social, crea también las condiciones para la instalación de una nueva «burguesía empresarial rural»: técnica-transnacional-neoliberal; pues la fuerza del accionar del Estado, junto a los movimientos sociales, logran desplazar al grupo tradicionalmente dominante, abriendo espacio a la emergencia de "nuevos emprendedores agrícolas", quienes junto a grandes negocios alimentarios transnacionales, son los actores que han fijado las prioridades productivas que definen la organización de los territorios en este país.

A su vez, como segundo rastro, las formas de organización de la distribución y tenencia de tierras, que acentúan el poder de negocios transnacionales, tiene sin lugar a dudas una estrecha relación con el despliegue de gran parte de los conflictos rurales que hoy en día se presentan; pues la especialización de territorios en producciones específicas, así como la utilización de agrotóxicos y transgénicos, tanto como el acaparamiento de tierras y la concentración de recursos productivos en pocas manos, dan cuenta del conjunto de relaciones que definen los marcos materiales y simbólicos en que se desenvuelven las luchas que los movimientos sociales rurales contemporáneos levantan en nuestros días.

Así como otrora los movimientos campesinos estuvieron asociados a la lucha por la tierra y la obtención de derechos laborales y civiles; desde los 90, los movimientos rurales muestran un giro en sus propuestas epistemológicas y han instalado, a nivel internacional, la importancia de la lucha por los territorios. El EZLN en México, los movimientos indígenas andinos 
de Bolivia y Ecuador, el MST de Brasil; todos hacen referencia a la importancia de entender los territorios como espacios geográficos que contiene dimensiones simbólicas, modos de habitar y ser en el mundo, afectos y conflictos, estéticas y éticas, además de condiciones productivas y jurídicas.

La instalación de la agenda territorial, muestra la huella que exige atención sobre la necesidad de encontrar otros lugares de resolución de conflictos, complementarios a los económicos y jurídicos ${ }^{11}$. La demanda es a una reflexión donde quepan otros actores y sus mundos simbólicos; donde sea posible buscar soluciones abigarradas $^{12}$, sobre la base de un pacto social democrático de convivencia.

Asoma, producto de las experiencias de reformas agrarias, la emergencia de ciertos grupos sociales constatando cómo la consolidación y legitimación de ciertos actores junto a sus demandas logran traspasar las barreras de la dominación hegemónica -colonial, clasista

Estas enunciaciones se alimentan de un pensamiento colectivo elaborado a partir de conversaciones mantenidas, fundamentalmente con María Paulina Soto Labbé, en el marco del proyecto investigativo que, bajo la promoción del Observatorio Itaú Cultural de Sao Paulo, se propone la creación y construcción del Índice de Convivencia Intercultural (ICI) de aplicación internacional.

12 René Zavaleta Mercado -sociólogo boliviano- instala en los 50-60 la idea de "sociedad abigarrada" haciendo referencia al reconocimiento de la inacabable unidad bajo la persistente heterogeneidad propia de la sociedad boliviana. Una sociedad abigarrada es una conformación desarticulada entre diversos modos de organización social, correspondientes a distintos tiempos, con mundos simbólicos y estructuras de autoridad diferentes. Posteriormente, Silvia Rivera Cusicanqui, asocia la noción aymara de ch'ixi a la de "sociedad abigarrada" de Zavaleta. Lo ch'ixi expresa una yuxtaposición de colores opuestos que muestran otro, cuya composición no homogeneiza la diversidad de colores que confluyen. Lo ch'ixi plantea "la coexistencia en paralelo de múltiples diferencias culturales que no se funden, sino que antagonizan o se complementan. Cada una se reproduce a sí misma desde la profundidad del pasado y se relaciona con las otras de forma contenciosa". (Rivera 2010: 70) y patriarcal-, instalando nuevas categorías (soberanía alimentaria, autonomías comunitarias, producción agroecológica y otras) que, desde los contornos de las luchas por la tierra, dan muestra de otras formas posibles de construir convivencias culturales, según cada país.

En América Latina, Bolivia será ejemplo emblemático -junto a Ecuador- en mostrar alternativas al respecto, pues son movimientos sociales de gran relevancia los que instalan lógicas socio-comunitarias indígenas en distintas formas de organización, llegando a reconfigurar los marcos constitucionales sobre premisas epistemológicas distintas a las tradicionales democracias liberales occidentales ${ }^{13}$. No obstante estos avances, son muchas las dificultades y reversos para aplicar efectivamente estos "nuevos contratos sociales"; cuyo mayor valor hasta ahora, por tanto, es lograr establecer grandes acuerdos sobre nuevos fundamentos plurales.

En Chile, en cambio, la propiedad privada individual se erige como uno de los principios sociales básicos sobre los que se dispone toda la estructura de desarrollo social. Siendo otro pilar fundamental la configuración ciudadana a través del Estado; es decir, la fuerza social y su emergencia se conciben principalmente a partir de su vinculación clientelar con las instituciones. A pesar de estas relaciones de dependencia entre actores colectivos y organismos públicos, la voz autónoma más fuerte es la del pueblo mapuche, enfrentando una lucha permanente por hacer respetar sus derechos humanos, territoriales y culturales. Aun cuando, en Chile actual, las

\footnotetext{
La discusión no se da en torno a la pertinencia o no de los sistemas democráticos, lo cual sería absurdo; sino más bien se desenvuelve en torno a los parámetros no cuestionables de las democracias donde parecieran existir consensos unívocos.
} 
organizaciones colectivas rurales se encuentran en posición de resistencia y fortalecimiento interno, el entretejido comunitario rural chileno está compuesto de múltiples actores colectivos organizados: sindicatos campesinos de larga trayectoria, organizaciones de mujeres indígenas y campesinas, organizaciones medioambientales y ecologistas, organizaciones no gubernamentales, activistas políticos, redes de individuos y familias. Organizaciones colectivas que, cada cierto tiempo, irrumpen con importantes manifestaciones sociales y mantienen una atención activa sobre las decisiones legislativas que implementan el modelo en curso. Desde nuestra perspectiva, siguiendo a Melucci, en Chile es evidente la existencia de innumerables acciones colectivas a nivel de relaciones cotidianas, que aun no logran generar la emergencia de un movimiento social como tal; más en estas comunidades invisibles es donde la realización de ciertas prácticas y saberes comunitarios pueden llegar a mostrar nuevas alternativas de organización política, pues en los procesos de creación de identidades colectivas se van desarrollando alternativas posibles.

Finalmente, los alcances que tienen los distintos momentos de transformación en la distribución de tierras en un país, va a depender de que, junto con la capacidad para transformar la figura física, jurídica y simbólica de la distribución de la tierra; se generen las disposiciones básicas para la creación de nuevas formas de habitar estos territorios, como por ejemplo, la creación de una Constitución Política Plural. Aunque no es suficiente, pues como dice Bauman: "Mientras que el derecho a la diferencia se concede a otros, el derecho a la indiferencia (léase: abstenerse de emitir juicio y actuar en consecuencia) es en general usurpado por las mismas personas que conceden el anterior derecho a los demás. Cuando la tolerancia mutua se combina con la indiferencia mutua, las comunidades culturales pueden vivir en estrecha proximidad, pero rara vez se hablarán entre ellas". (Bauman 2013: p.55)

Bolivia avanzó en la enunciación de categorías, planteamientos de ideas, filosofías, prácticas comunitarias y bases éticas que desafiaron los códigos hegemónicos colonizadores que componían su antiguo contrato social, sin esencializar, ni retrotraer en el tiempo a los movimientos indígenas y campesinos; mientras Chile, ante la posibilidad finalmente de poder elaborar una Constitución democrática con amplia participación social, se están privilegiando una vez más mecanismos elitistas que definen lo razonablemente mejor para todos y todas.

\section{Conclusiones}

Los procesos de Reformas Agrarias en Bolivia y Chile son disímiles. Cuenta de ello es que inician en distintos momentos de la historia latinoamericana, bajo distintos propósitos iniciales, con distintas composiciones socioeconómicas y culturales, mostrando también diferentes formas de vinculación entre Estado y relaciones comunitarias. No obstante, en ambos países encontramos la experiencia y la memoria de reformas agrarias en que la distribución de la tierra tuvo o tiene como propósito primordial generar importantes transformaciones sociales, culturales y productivas.

En Bolivia, a partir de los 80 , se crea una importante fuerza emancipadora desde territorios rurales, con un alto componente identitario indígena, que reclama la redistribución 
de territorios, proponiendo la transformación de la matriz colonial en un amplio sentido. Se proponen nuevos saberes, epistemologías y cosmovisiones que exigen ser validados en complementariedad a la racionalidad técnica occidental, bajo el propósito de configurar una organización común que reconozca la pluralidad de proyectos culturales en desarrollo bajo un mismo Estado. Más, con la actual prolongación de cierto oligopolio en el poder, junto a la institucionalización de los movimientos sociales, finalmente el discurso oficial representa a una fracción de dirigentes comprometidos con la consecución del gobierno y sus mandatos, separados de sectores de la población que antes componían su fuerza política, mientras los movimientos sociales se han fragmentado, debilitado y clandestinizado.

En Chile, las principales formas comunitarias se organizan principalmente en resistencias 0 relaciones clientelares, con grandes dificultades para consolidar experiencias cercanas a las autonomías comunitarias. No obstante, el pueblo mapuche persiste en la práctica de relaciones comunitarias propias, muchas veces confrontándose directamente con el sistema de poder hegemónico que niega persistentemente su posibilidad auténtica de realizarse.

Así, las pretensiones transformativas de las reformas agrarias, paradójicamente, terminaron siendo funcionales a la emergencia de «emprendedores agrícolas» y la consolidación de negocios transnacionales extractivos de recursos naturales y exportadores alimentarios.

Como hemos visto, en Bolivia, este fenómeno se concentró en las tierras de los llanos orientales.
Situación que no ha sido transformada ni por la ley INRA ni por la ley de Reconducción comunitaria, aun cuando ésta última, al principio, sí tuvo incidencia en la redistribución de tierras a comunidades indígenas campesino originarias. Hemos visto que en Chile la estructura de tenencia de la tierra presenta niveles mayores de concentración que bajo la estructura hacendal, lo que da cuenta del nivel de desigualdad y fragilidad al que se enfrentan las familias campesinas, comunidades indígenas, cooperativas agrícolas, trabajadoras/ es temporales; haciendo comprensible a su vez los bajos, aunque crecientes, niveles de organización comunitaria en territorios rurales chilenos.

Pues también sabemos que la sola presencia en marcos jurídicos, más algunas intervenciones institucionales, muchas veces concertadas con intereses de capitales transnacionales, no son suficientes para emprender transformaciones de largo alcance como pueden ser los procesos de redistribución de tierras. Muestra de ello es la necesidad de ciertos actores colectivos por crear condiciones y capacidades que permitieran levantar las exigencias por el reconocimiento y la equiparación de derechos para indígenas, afrodescendientes, mujeres y hasta la naturaleza. Seguimos a Melucci, al plantear que estos actores han enunciado nuevas categorías que desafían los códigos hegemónicos, pues proponen la creación de nuevas pautas de comportamiento y novedosas formas de organización, desde otro horizonte simbólico. Sin duda, en territorios rurales contemporáneos de Bolivia y Chile, resulta primordial la lucha por una reforma agraria desde una orientación cultural. 


\section{Bibliografía}

Antezana, L. 2011. Latifundio y minifundio en Bolivia. La Paz: Plural editores.

Arruda Sampaio, P. 2012. "Notas críticas sobre a atualidade e os desafios da questão agraria". En línea, disponible en: http:// www.albamovimientos.org/wp-content/uploads/2012/11/1209QAufsc.pdf (consultado en octubre 2015)

Barraclough, S. et. al. 1973. "Chile: Reforma Agraria y Gobierno Popular". Buenos Aires: Ediciones Periferia. En línea, disponible en: http://www.blest.eu/biblio/barraclough/cap1. html (consultado en septiembre 2015)

Bauman, Z. 2013. "La cultura en el mundo de la modernidad líquida". México D.F: Fondo de Cultura Económica.

Bengoa, J. 1983. "El campesinado chileno después de la Reforma Agraria". Santiago: Ediciones Sur. Colección Estudios Sociales.

Bretón, V. 2006. "Glocalidad y reforma agraria ¿de nuevo el problema irresuelto dela tierra?". Íconos Revista de Ciencias Sociales N²4: 59-69.

Colque, G., Tinta, E., Sanjínes, E. 2016 (segunda edición). "Segunda reforma agraria: una historia que incomoda". La Paz: Fundación Tierra.

Corporación de la Reforma Agraria. 1970. La Reforma Agraria Chilena 1965-1970. Santiago.

Correa, M., Molina, R., Yáñez, N. 2005. "La Reforma Agraria y las tierras mapuche. Chile 1962-1975" Santiago: LOM Ediciones.

Chonchol, J. 2006. Reforma y Contrarreforma agraria en Chile. Santiago: FAO.

Chumacero, J. (coord.). 2010. "Trece años de reforma agraria en Bolivia. Avances, dificultades y perspectivas". Reconfigurando territorios: reforma agraria, control territorial y gobiernos indígenas en Bolivia. La Paz: Fundación Tierra. 11-38.

Decreto de Ley 2247. 1978. Santiago.

Garrido, J. (ed); Guerrero, C.; Valdés M. S. 1988. Historia de la Reforma Agraria en Chile. Santiago: Editorial Universitaria.

Gómez, M. 2006. "El estado de la agricultura chilena y sus transformaciones y modernización" Observatorio de la Economía Latinoamericana 62. En línea, disponible en: www.eumed.net/ cursecon/ecolat/cl/

Gómez, S. 1993. "El rol del sector agrario en la transición. Análisis del caso chileno". Revista Agricultura y Sociedad №68: 81-108. (consultado en octubre 2015)

Jemio-Ergueta, Á. 1973. "La Reforma Agraria de Bolivia". Revista Nueva Sociedad N²: 19-37.

Kay, C. 1999. "Mirando hacia atrás: el tiempo de las reformas agrarias". Revista Envío №208-209.

Ley $\mathrm{N}^{\circ}$ 1715. 1996. La Paz.

Ley N¹6640. 1967. Santiago.

Lizarraga, P., Vacaflores. C. 2014. "La descolonización del territorio: luchas y resistencias campesinas e indígenas en
Bolivia". Capitalismo: tierra y poder en América Latina (19822012). Volumen II. Almeyra, G., Concheiro, L., Mendes, J., PortoGoncalves, C.(coords). Buenos Aires: UAM, CLACSO, Ediciones Continente.

Melucci, A. 1999. "Acción colectiva, vida cotidiana y democracia". México D.F: El Colegio de México.

Ministerio de Desarrollo Rural y Medio Ambiente; Viceministerio de Tierras; Instituto Nacional de Reforma Agraria. 2007. "Plan Estratégico Nacional de Saneamiento y Titulación de Tierras 2007-2013". La Paz

Nuñez, E. 2007. Reconducción comunitaria de la Reforma Agraria en Bolivia. CIPCA. En línea, disponible en: http://www. cipca.org.bo/index.php/cipca-notas/cipca-notas-2007/444-sp-1848725135 (consultado en julio 2015)

PNUD. 2004. Informe de Desarrollo Humano en Santa Cruz 2004. La Paz: Plural editores.

Rivera, S. 2010. "Ch'ixinakax utxiwa. Una reflexión sobre prácticas y discursos descolonizadores". Buenos Aires: Tinta Limón ediciones.

Romero B, C. 2008. La tierra como fuente de poder: económico, político y cultural. Santa Cruz: IGWIA - ISBOL.

Ruiz, A; Becerra, A. 2011. Chile Potencia Alimentaria y Forestal: la extensión del modelo exportador al mundo rural y sus consecuencias sociales. Santiago: Fundación CENDA y Fundación Heinrich Böll.

Santana U., R. (2006): Agricultura chilena en el siglo XX: contextos, actores y espacios agrícolas. Centro de Estudios Regionales Universidad de Los Lagos y Centro de Investigaciones Diego Barros Arana. DIBAM. Santiago de Chile.

Soliz, L; Núñez, E. 2013. "A 60 años de la Reforma Agraria en Bolivia: cambio y continuidad”. Revista Mundos Rurales N9: 2-7.

Ticona, E. 2004. "La Revolución Boliviana de 1952 y los Pueblos Indígenas". Revista Temas Sociales N²5: 1-14.

Tinsman, H. 2009. "La tierra para el que la trabaja: géneros, sexualidad y movimientos campesinos en la Reforma Agraria chilena". Santiago: LOM Ediciones y Centro de Investigaciones Diego Barros Arana.

Urioste, Miguel. 2003. "La Reforma Agraria abandonada: valles y altiplano". Proceso agrario en Bolivia y América Latina. CLACSO. Bolivia: Plural editores y CIDES-UMSA, POSGRADO EN Ciencias del Desarrollo. 19-52.

Urioste, Miguel. 2014. "La cuestión de quién suministra los alimentos en Bolivia". Ponencia presentada en el Seminario Recientes Transformaciones Agrarias en Bolivia, realizado por Fundación Tierra.

Vargas, J. (editor) 2004. "La reforma agraria desde las regiones: tierra y territorio". La Paz: CIDES-UMSA, CIPCA, Fundación Tierra, CEJIS, ACLO, G-DRU, UARPSFXCH, UAGRM, AIPE, Secretariado Rural Perú Bolivia, DANIDA, DFID, Plural Editores. 
